\title{
Heterotopic mesenteric ossification: report of a case and review of the literature
}

\author{
Fariba Binesh, ${ }^{1}$ Ali Akhavan, ${ }^{2}$ Hossein Navabiii, ${ }^{3}$ Mussa Ostadi ${ }^{4}$ \\ ${ }^{1}$ Department of Pathology, Yazd Shahid Sadoughi University, Yazd, Iran, Islamic Republic of Iran \\ ${ }^{2}$ Department of Radiotherapy, Shahid Sadoughi University of Medical Science, Yazd, Iran, Islamic Republic of Iran \\ ${ }^{3}$ Shahid Sadoughi University of Medical Science, Yazd, Iran, Islamic Republic of Iran \\ ${ }^{4}$ Department of Radiology, Shahid Sadoughi University of Medical Science, Yazd, Iran, Islamic Republic of Iran
}

Correspondence to Dr Fariba Binesh, binesh44@yahoo.com

\section{Summary}

Heterotopic mesenteric ossification (HMO) is a distinct intra-abdominal ossifying pseudotumour that typically occurs in men, almost always after surgery or abdominal trauma, and frequently presents with symptoms of intestinal obstruction. We herein describe a case of HMO occurring in a 42-year-old Iranian man with a history of abdominal blunt trauma. He underwent partial small intestinal and its mesentery resection. The postoperative course was uneventful. Now he is in good condition after 6 months.

\section{BACKGROUND}

Deposits of amorphous calcium without osteoblasts are known as dystrophic calcification and are frequent in human pathology, whereas calcium deposits with simultaneous presence of osteoblasts and bone layers are known as heterotopic ossification ( $\mathrm{HO}$ ) and are quite rare. ${ }^{1} \mathrm{HO}$ is a general term used to describe the formation of bone in a tissue that normally does not ossify. ${ }^{2}$ It is an unusual finding in the immediate vicinity of skeletal bone, but in soft tissues, it is very rare. ${ }^{3}$

Heterotopic mesenteric ossification ( $\mathrm{HMO}$ ) is a rare intra-abdominal bone-producing pseudosarcoma with few reported cases in the literature. The significance of this non-neoplastic process is threefold: (1) patients often present with significant abdominal symptoms, (2) the process tends to worsen or recur after repeat laparatomy and (3) rare forms of malignant neoplasms such as extraskeletal osteosarcoma may have a similar appearance. We herein report one case of $\mathrm{HMO}$, and discuss the pathological features and outcome.

\section{CASE PRESENTATION}

A 42-year-old man, previously in good health, presented with severe abdominal pain after being in a motor vehicle crash. Radiographs showed no pelvic ring injury. An initial CT scan of the abdomen demonstrated mild laceration of the spleen and liver, but with no signs of active bleeding. There were no signs of bowel injury. Following stabilisation, the patient was discharged in good condition. After 4 months he was readmitted due to severe crampy abdominal pain.

\section{INVESTIGATIONS}

Abdominal CT scan showed a few air fluid level and in the right lateral aspect of peritoneum, there was an abnormal thickening (figure 1). On the basis of CT aspect of the lesion, the surgeon suggested explorative laparatomy. The specimen submitted for pathological examination consisted of $16 \mathrm{~cm}$ of small bowel as well as adherent fibrofatty tissue with a $2.5 \times 1 \mathrm{~cm}$ firm nodule which had gritty consistency. The histological examination revealed small bowel wall and its mesentery with foci of spindle cell proliferation, areas of fibrosis and osteoid formation without prominent mineralizsation surrounded by inflammatory cells (figures 2 and 3). The diagnosis was HMO.

\section{DIFFERENTIAL DIAGNOSIS}

The differential diagnosis for intra-abdominal densities after trauma or surgical exploration should include: $\mathrm{HO}$, dystrophic calcification, osseous neoplasia, oral contrast extravasation and foreign material. ${ }^{4-6}$ Distinguishing among them radiologically may require a high degree of clinical suspicion. Densities with a well-defined cortex and internal trabecular pattern on imaging suggest mature bone rather than contrast leakage or dystrophic

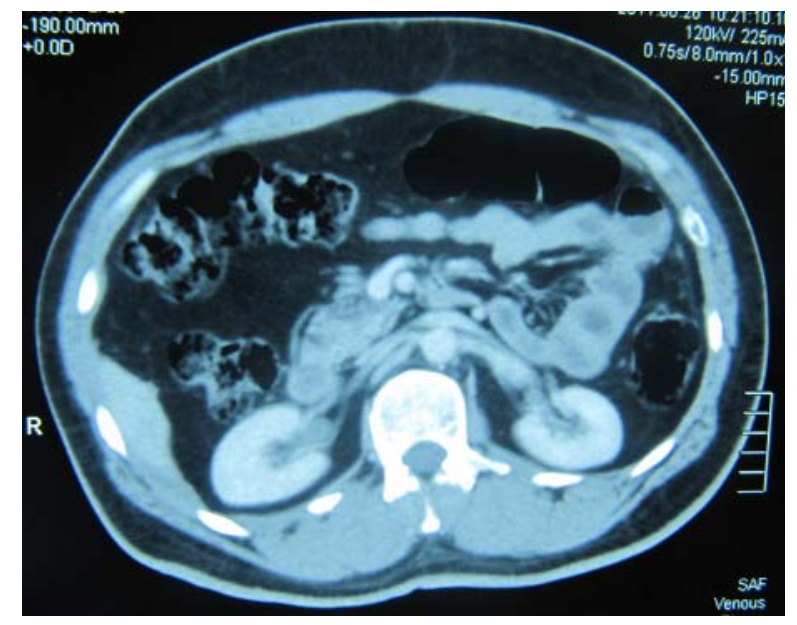

Figure 1 CT scan (axial plane) shows a few air fluid level and in the right lateral aspect of peritoneum there is an abnormal thickening. 


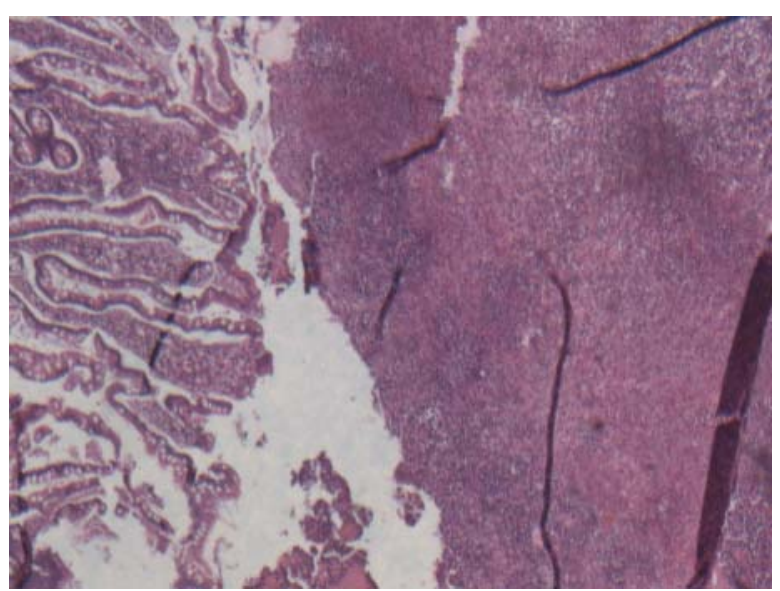

Figure 2 Section shows small bowel wall with inflammatory cell infiltration and spindle cell proliferation (H\&E $\times 10$ ).

calcification. Dystrophic calcification typically causes faint radiodense areas that are punctate and irregular. However, oral contrast leakage will evolve on serial images with collection occurring in dependent areas ${ }^{4-6}$ and there will be no internal structure. The difficulty and importance of microscopically distinguishing the present reactive lesion from a sarcomatous process is noteworthy. The clinical history, presence of clearly reactive zones, thick osteoid and absence of nuclear atypia, necrosis and atypical mitotic figures allow the distinction of $\mathrm{HO}$ from its most important morphological mimic, extraskeletal osteosarcoma. Additionally, mineralised neoplasms such as extraskeletal osteosarcoma or extraskeletal chondrosarcoma generally show irregular, immature growth patterns rather than the mature trabecular bone seen in $\mathrm{HO}$. It should be noted that HMO may show a number of histological features that raise concern for an extraskeletal osteosarcoma, including high cellularity, frequent mitotic figures and somewhat 'lace-like' osteoid production. Helpful diagnostic features include a distinctly zonated growth pattern, similar to myositis ossificans. In contrast, extraskeletal osteosarcoma frequently shows a pattern of

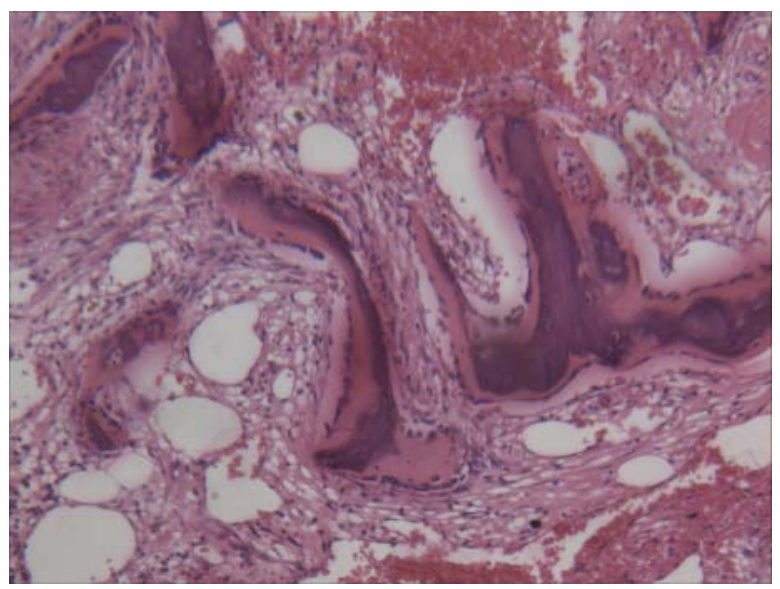

Figure 3 Section shows areas of fibrosis and osteoid formation without prominent mineralisation surrounded by inflammatory cells $(\mathrm{HEE} \times 40)$. 'reverse zonation', with increasingly immature appearing cells and matrix at the periphery, rather than the centre of the lesion.

\section{TREATMENT}

The patient underwent explorative laparatomy. At surgery, the surgeon found massive adhesions involving small intestine and a firm fibrous tissue within the omentum, encapsulating the jejunum and the proximal small intestine. Adhesiolysis and a partial omentectomy and jejunectomy were performed.

\section{OUTCOME AND FOLLOW-UP}

The postoperative course was uneventful, with regular bowel functions. The patient was discharged 1 week after the operation. He is currently (after 6 months) disease free and in good condition.

\section{DISCUSSION}

$\mathrm{HMO}$ is a rare intra-abdominal bone-producing pseudosarcoma with few reported cases in the literature. It is also known by other names, including pseudomalignant osseous tumour of soft tissue, myositis ossificans, neurogenic osteoma, fibrositis ossificans and fibrodysplasia ossificans. $^{8}$ Myositis ossificans first described in detail by Ackerman, ${ }^{9}$ is perhaps the best-known example of $\mathrm{HO}$ in the somatic soft tissue. The term 'HMO' was coined by Wilson et al in 1999, in their description of five intra-abdominal ossifying pseudotumour, histologically identical to myositis ossificans. ${ }^{10}$ It most frequently affects the musculature, typically in the lower extremities, but can also be observed in tendons, fasciae, subcutaneous fat and periosteum. ${ }^{11}$ Rare lesions occur intra-abdominally, with the most common location being in the mesentery. It has been known to occur in laparatomy scars and with mucinous epithelial tumours. ${ }^{12}$ It is a distinct intra-abdominal ossifying pseudotumour that typically occurs in men, almost always after surgery or abdominal trauma, and frequently presents with symptoms of intestinal obstruction. The masses are typically discovered by the doctor at a postsurgical follow-up appointment, or when a patient complained of abdominal pain and/or discomfort. Our case was a 42-year-old Iranian man with a history of blunt abdominal trauma and had severe abdominal crampy pain that was suggestive of partial abdominal obstruction. Although $\mathrm{HMO}$ occurs predominantly in men, three cases also occurred in women. $\mathrm{HO}$ has been discovered as early as 11 days after surgery or trauma and as late as 30 postsurgical years. ${ }^{13}$ In the majority of patients ossification had formed between 4 and 6 months following surgery. In our case, it was 4 months. If little or no history is available, the diagnosis can be particularly problematic because of its rarity. For example, Hakim and McCarthy ${ }^{4}$ reported a case of a 50-year-old man presenting with bowel obstruction who had a history of a stab wound to the left flank 2 years earlier. A preoperative abdominal radiograph showed densities that were thought to be barium extravasation, but at surgery, heterotopic bone was found obstructing the bowel. A postoperative CT not only described some residual $\mathrm{HO}$ but also misinterpreted it as barium extravasation. This illustrates the high level of suspicion needed to accurately diagnosis this entity and also the importance of history in context of the study. Additionally, Tonino et al described a 
similar case of multiple gunshot wounds to the abdomen in which a CT scan 1 month later was read as oral contrast medium leakage although the exact location of leakage could not be found. In our case, a barium contrast study was not performed, thus excluded the possibility of barium extravasation. Also in presented case, because morphological features suggesting malignancy such as nuclear atypia, necrosis and atypical mitotic figures were absent, the differential diagnosis from malignant bone neoplasms was quite easy. The preoperative diagnosis of $\mathrm{HMO}$ is difficult, although a trabecular architecture as seen radiographically is highly suggestive of ossification, and a CT scan may provide confirmatory evidence. ${ }^{4}$ In presented case CT scan showed a few air fluid level and in the right lateral aspect of peritoneum there was an abnormal thickening and he had symptoms which were suggestive of partial obstruction. HMO should be recognised radiologically and distinguished from other conditions for two important reasons. First HMO may cause bowel obstruction and even death because of intestinal perforation. Second $\mathrm{HMO}$ tends to recur. ${ }^{8}$ The pathogenesis of $\mathrm{HO}$ is still unknown, but it is generally considered to represent a reactive process in response to a variety of stimuli. Chalmers et al ${ }^{14}$ proposed three conditions necessary for osteogenic induction: (1) osteogenic precursor cells, (2) a permissive environment and (3) a stimulus. Mesenchymal cells have the ability to generate cartilage, bone and muscle, but cannot differentiate without stimulating agents. What is the trigger agent for osteogenic induction? Ossification of the peritoneum has been reported in response to spilled contents of mature cystic teratoma, suggesting metaplastic pathogenesis in response to chemical or physical stimuli. ${ }^{15}$ Another hypothesis is that the trigger may be an infectious/inflammatory stimulus. ${ }^{16}$ Such stimuli would act on stem cells to regenerate mesoblasts, at the same time erroneously stimulating generation of osteoblasts. ${ }^{17}$ According to Peck et al, ${ }^{18}$ the monocyte-macrophage series may play multiple roles in bone metabolism and, in some cases, they appear to act as osteoblasts, elaborating various substances that promote osteoblast activity; in particular, resident peritoneal macrophages elaborate a 42000 Dalton heat-stable protein that is a potent growth stimulator of osteoblasts and chondrocytes. In addition, the largest case review (52 cases) of osseous metaplasia in the gastrointestinal tract was done by Ansari et al. ${ }^{19}$ They found out that benign lesions with osseous metaplasia were often seen with a histological background of active chronic inflammation and/or ulceration. Additionally, Dobbie, ${ }^{20}$ Ohmori et al, ${ }^{21}$ Rigby and Hawley ${ }^{22}$ and Jones et al showed that inflammatory pathology plays a particular role in $\mathrm{HMO}$. In our case we observed that inflammatory cells had surrounded areas of ossification and it suggests that macrophages, giant cells and leukocytes may play a role in activating mesenchymal cells that differentiate into osteoblasts. Of course, there may be other factors still unknown. ${ }^{18}$ Surgery is the treatment of choice, even if recurrence in such cases is frequent. Some cases of HMO have been reported to recur after two or more operations in previous studies in the literature. ${ }^{10}$ Treatments that have been suggested to decrease regrowth, include anti-inflammatory medications, bisphosphonates and radiotherapy. ${ }^{35}$ We were unable to find any cases documented in the literature in which $\mathrm{HMO}$ has undergone malignant degeneration.

\section{Learning points}

- Pain is the main symptom in symptomatic heterotopic mesenteric ossification (HMO) cases. Patients often present with significant abdominal symptoms. It usually arises due to the obstruction of passage or organ lumen.

- A preoperative diagnosis is often difficult, and this may lead to serious complications and even sometimes death. High level of suspicion, patient's history and radiography are needed to accurately diagnosis this entity.

- Surgery is the modality of choice, it can be diagnostic and therapeutic, although some cases of HMO have been reported to recur after two or more operations in previous studies.

- HMO may show a number of histological features that raise concern for an extraskeletal osteosarcoma, including high cellularity, frequent mitotic figures, somewhat 'lace-like' osteoid production. Helpful diagnostic features include a distinctly zonated growth pattern, similar to myositis ossificans.

\section{Competing interests None.}

Patient consent Obtained.

\section{REFERENCES}

1. Kewalramani LS, Orth MS. Ectopic ossification. Am J Phys Med 1977:56:99-121.

2. Cohly HH, Buckley RC, Pecunia R., et al. Heterotopic bone formation of an experimental rat model and a clinical case. Biomed Sci Instrum 2003;39:446-53.

3. Angervall L, Stener I. Pseudomalignant osseous tumor of soft tissue. A clinical, radiological and pathological study of five cases. J Bone Joint Surg Br 1969;51:654-63.

4. Hakim M, McCarthy EF. Heterotopic mesenteric ossification. Am J Roentgenol 2001;176:259-60.

5. Zamolyi RQ, Souza P, Nascimento AG, et al. Intraabdominal myositis ossificans: a report of 9 new cases. Int J Surg Pathol 2006;14:37-41.

6. Gouello JP, Auvray L, Bouix A, et al. Early post-traumatic heterotopic mesenteric ossificationof a case. Intensive Care Med 2006:32:950-1.

7. Tonino BA, van der Meulen $\mathrm{HG}$, Kuijpers $\mathrm{KC}$, et al. Heterotopic mesenteric ossification: a case report (2004:10b). Eur Radiol 2005;15:195-7.

8. Myers MA, Minton JP. Heterotopic ossification within the small bowel mesentry. Arch Surg 1989;124:982-3.

9. Ackerman LV. Extra-osseous localized non-neoplastic bone and cartilage formation (so-called myositis ossificans): clinical and pathological confusion with malignant neoplasm. J Bone Joint Surg Am 1958;40:279-98.

10. Wilson JD, Montague CJ, Salcuni P, et al.. Heterotopic mesenteric ossification (intraabdominal myositis ossificans): report of five cases. Am J Surg Pathol 1999;23:1464-70.

11. Haque S, Elsen RN, West BA. Heterotopic bone formation in the gastrointestinal tract. Arch Pathol Lab Med 1996;120:666-70.

12. Weiss SW, Goldblum JR. Enzinger and Weiss's soft tissue tumors. 5th edn. St. Louis, MO: Mosby, 2008:1039-59.

13. Gaffey MJ, Winston DC. Heterotopic ossification of soft tissue: a review with emphasis on ossification within abdominal surgical scars. In: Fechner $\mathrm{NE}$, Rosen PP, eds. ASCP reviews in pathology, anatomical pathology, Vol. 3. Chicago, IL: American Society of Clinical Pathology, 1998:195-208.

14. Chalmers J, Gray DH, Rush J. Observations on the induction of bone in soft tissues. J Bone Joint Surg Br 1975;57:36-45.

15. Bhardwaj S, Bal A, Mohan H. Heterotopic omental ossification in response to spilled contents of a maturecystic teratoma: an unusual reaction. Histopathology 2002;41:559-67.

16. Fadare 0, Bifulco C, Carter D, et al. Cartilaginous differentiation in peritoneal tissues: a report of two cases and a review of the literature. Mod Pathol 2002;15:777-80. 


\section{BMJ Case Reports}

17. Garosi G, Di Paolo N. Inflammation and gross vascular alterations are characteristic histological features of sclerosing peritonitis. Perit Dial Int 2001;21:417-18.

18. Peck WA, Rifas L, Shen V. Macrophages release a peptide stimulator of osteoblast growth. Ann Biol Clin (Paris) 1985;43:751-4.

19. Ansari MQ, Sachs IL, Max E, et al. Heterotopic bone formation in rectal carcinoma. Case report and literature review. Dig Dis Sci 1992;37:1624-9.
20. Dobbie JW. Pathogenesis of peritoneal fibrosing syndromes (sclerosing peritonitis) in peritoneal dialysis. Perit Dial Int 1992;12:14-27.

21. Ohmori T, Ohnishi S, Okada K, et al. Sclerosing encapsulating peritonitis and non-occlusive mesenteric infarction found at autopsy in a man who had undergone continuous peritoneal dialysis: a histochemical and immunohistochemical study. Pathol Int 2000;50:660-6.

22. Rigby RJ, Hawley CM. Sclerosing peritonitis: the experience in Australia. Nephrol Dial Transplant 1998;13:154-9.

This pdf has been created automatically from the final edited text and images

Copyright 2012 BMJ Publishing Group. All rights reserved. For permission to reuse any of this content visit http://group.bmj.com/group/rights-licensing/permissions.

BMJ Case Report Fellows may re-use this article for personal use and teaching without any further permission.

Please cite this article as follows (you will need to access the article online to obtain the date of publication).

Binesh F, Akhavan A, Navabii H, Ostadi M. Heterotopic mesenteric ossification: report of a case and review of the literature. BMJ Case Reports 2012;10.1136/bcr-02-2012-5793, Published XXX

Become a Fellow of BMJ Case Reports today and you can:

- Submit as many cases as you like

- Enjoy fast sympathetic peer review and rapid publication of accepted articles

- Access all the published articles

- Re-use any of the published material for personal use and teaching without further permission

For information on Institutional Fellowships contact consortiasales@bmjgroup.com

Visit casereports.bmj.com for more articles like this and to become a Fellow 